\title{
Alocação sexual e seleção sexo-dependente para tamanho de corpo em Trypoxylon rogenhoferi Kohl (Hymenoptera, Sphecidae)
}

\author{
Rui Carlos Peruquetti ${ }^{1,2}$ \\ Marco Antônio Del Lama ${ }^{1}$
}

\begin{abstract}
Aвstract. Sex allocation and sex-dependent selection for body size in Trypoxylon rogenhoferi Kohl (Hymenoptera, Sphecidae). Two populations of the wasp Trypoxylon rogenhoferi Kohl, 1884 from São Carlos and Luís Antônio, State of São Paulo, Brazil, were observed and sampled from May 1999 to February 2001 using trap-nests. This mass-provisioning wasp was used to test some aspects of optimal sex allocation theory. Both populations fit all the predictions of the models of Green and Brockmann and Grafen. Maternal provisions determined the size of each offspring, and females allocated wellstocked brood cells to daughters, the sex that benefits most being large. This strategy resulted in a difference in size between the sexes. In São Carlos, female weight at emergence was 1.18 times that of males, in Luís Antônio this value was 1.13. The brood cell volume was correlated with both wing length and weight at emergence in both sexes, and the chance that a given brood cell contained a male offspring decreased with increased brood cell volume. In $T$. rogenhoferi female body size was related to fitness. Larger females were able to collect more mass of spiders per day, the spiders they captured were heavier, and they provisioned more brood cells per day. They also produced larger daughters. For males, no relationship between body size and fitness was found, but the data were scarce. Since the patterns of provisioning were variable among different females in both study sites, it is possible that the females not follow a unique strategy for sex allocation. The sex ratio and/ or investment ratio in the São Carlos population was female-biased and in Luís Antônio, male-biased. In spite of the influence of trap-nests diameters on male production in Luís Antônio, there is some evidence that in São Carlos population the local availability of prey and/or lower rate of parasitism may be major forces in determining the observed sex ratio, but further studies are necessary to verify such hypothesis.
\end{abstract}

KEYwORDs. Body size; cerrado; mass provisioning; sex ratio; trap-nesting wasp.

\section{INTRODUÇÃO}

O sistema haplodiplóide de determinação do sexo permite que a fêmea controle o sexo de sua prole. Este controle está sob influência ambiental e ocorre no momento da oviposição. Os óvulos fertilizados produzirão fêmeas e os não-fertilizados, machos (Flanders 1965; Crozier \& Pamilo 1996). Assim, assimetrias de parentesco são geradas entre os membros da família e podem ocorrer conflitos de interesse entre machos e fêmeas no momento da determinação do sexo da prole (TRIVERS $\&$ HARE 1976). Na maioria das populações panmíticas esperase investimentos igualitários em ambos os sexos e razão sexual próxima de 1:1 (FISHER 1930). Porém, em himenópteros aculeados (abelhas, formigas e algumas vespas) há desvios desta proporção, freqüentemente atribuídos a fatores ecológicos, fisiológicos e comportamentais. Entender a natureza e evolução destes desvios é um dos objetivos de estudos sobre a evolução da socialidade em Hymenoptera (Trivers \& HARE 1976; Alexander \& Sherman 1977; Frohlich \& Tepedino 1986; Brockmann \& Grafen 1992; Helms 1994; Deslippe \& SaVolainen 1995; Crozier \& Pamilo 1996; Yanega 1996; Chapuisat \& Keller 1999; Strohm \& Linsenmair 1997a, 1997b, 1999; Оки \& NishiDA 1999, 2001).

Abelhas e vespas que aprovisionam suas células de cria de forma massal (isto é, todo o alimento é disponibilizado à larva pela mãe de uma única vez) são particularmente interessantes para estudos sobre alocação sexual (BouRKE 1997; Molumby 1997; S Trohm \& LinsenMair 1999, 2000). Nestes casos, assim como acontece com algumas vespas parasitóides (GAULD \& Hanson 1995), o sucesso reprodutivo da prole depende do

1. Laboratório de Genética Bioquímica, Departamento de Genética e Evolução, Universidade Federal de São Carlos. Caixa Postal 676, 13565-905 São Carlos-SP, Brasil.

2. Endereço atual: Laboratório de Biologia Molecular, Departamento de Biologia Geral, Universidade Federal de Viçosa. 36571-000 Viçosa-MG, Brasil. Endereço eletrônico: peruquetti@bol.com.br 
fenótipo materno (principalmente tamanho e vigor) e das escolhas feitas pela mãe no momento da oviposição. Esta influência direta da mãe sobre sua prole, em vários casos, é responsável por grande parte da variação de tamanho de corpo nas populações destas espécies (KIRKPATRICK \& LANDE 1989; Molumby 1997; Mousseau \& Fox 1998; S TROHM \& LinsEnMaIR 1997a).

Os modelos de Green (1982) e Brockmann \& Grafen (1992) para explicar a alocação sexual ótima sob variação aleatória de recursos pressupõem que: (1) a provisão oferecida à cada larva varia de acordo com uma distribuição aleatória contínua; (2) o valor adaptativo de cada adulto depende da provisão dada a cada larva; (3) o valor adaptativo de machos e fêmeas é afetado diferentemente pela quantidade de provisão que eles receberam e, (4) a fêmea pode determinar o sexo de cada prole de acordo com a provisão disponível. Caso a provisão larval influencie o tamanho do corpo, os modelos predizem que a fêmea poderá destinar as células melhor estocadas (ou hospedeiros maiores) ao sexo que mais se beneficiar do maior tamanho. Assim, dimorfismo sexual para tamanho do corpo pode ser resultado de uma estratégia adaptativa de aprovisionamento adotado pela mãe.

Neste estudo foi examinada a alocação diferenciada de recursos e seus efeitos no valor adaptativo de cada sexo em Trypoxylon rogenhoferi Kohl, 1884, uma espécie comum em quase todo território brasileiro que nidifica em cavidades preexistentes, apresenta aprovisionamento massal das células de cria e dimorfismo sexual para tamanho do corpo.

\section{MATERIAL E MÉTODOS}

Local de estudo e método de amostragem. Foram estudadas, de maio de 1999 a fevereiro de 2001, duas populações de $T$. rogenhoferi de duas localidades do Estado de São Paulo: São Carlos (SC; Fazenda Canchim, EMBRAPA; 2201'S, 4753'W) e Luís Antônio (LA; Estação Ecológica Jataí; 21²5'S, 4750’W). Estas populações foram amostradas com a técnica de ninhosarmadilha (KROMBEIN 1967). Os ninhos foram construídos com gomos de bambu com cerca de $20 \mathrm{~cm}$ de comprimento e diâmetro variável (7 a $19 \mathrm{~mm}$ ), abertos em uma extremidade e fechados na outra pelo próprio nó. Ambas as localidades possuem áreas de cerrado, floresta semidecídua, corpos d'água e áreas com pastagem, ambientes que oferecem condições ideais para a ocorrência e nidificação de T. rogenhoferi. A população de LA nidifica há, pelo menos, 25 anos (H. Gomes, comunicação pessoal) no local onde foram instalados os ninhos-armadilha. Na população de SC, o número de indivíduos tornou-se maior no local de amostragem apenas depois da instalação dos ninhos-armadilha. Esta diferença no tempo de uso das áreas de nidificação pode promover diferenças nas pressões dos parasitas de espécies que nidificam em cavidades preexistentes (WCISLO 1996).

Espécie estudada. No Brasil, T. rogenhoferi é bastante comum. As fêmeas constróem seus ninhos solitariamente em cavidades preexistentes, tais como ninhos abandonados de outras vespas (sociais ou solitárias) ou túneis feitos em madeira por outros insetos. Túneis longos são subdividos com paredes de barro. Assim, são formadas diferentes células de cria, variando de uma a 12, dependendo da extensão utilizada. Cada célula é aprovisionada com três a 20+ aranhas paralizadas. Um único ovo é colocado na última aranha depositada em cada célula de cria. A fundação de ninhos ocorre ao longo de todo ano, mas o período quente e úmido é o de maior atividade.

$\mathrm{O}$ macho de $T$. rogenhoferi pode tomar conta do ninho durante o período de aprovisionamento, como ocorre em outros membros do subgênero Trypargilum Richards, 1934. Nessa função, ele se posiciona no interior da cavidade de nidificação, próximo às aranhas armazenadas e, periodicamente, inspeciona a entrada do ninho e repele parasitas e/ou coespecíficos de ambos os sexos que tentem entrar no ninho. Este macho copula repetidamente com a fêmea quando esta retorna ao ninho, especialmente antes de ocorrer a oviposição. Cópulas extrapar também ocorrem, frequentemente, à entrada do ninho, onde a fêmea pousa ao retornar transportando barro ou aranha. Machos que não estão guardando ninhos patrulham as áreas de nidificação à procura de ninhos ainda não ocupados por outros machos. Quando ninhos vazios são encontrados, os machos permanecem neles até que uma fêmea entre na cavidade. Então, ocorre cópula e o ninho começa a ser construído.

Dados sobre a biologia de $T$. rogenhoferi podem ser encontrados em CAMILlo et al. (1994), GARCIA \& Adis (1995) e CAmillo \& Brescovit (1999).

Coleta dos ninhos. Em ambas as áreas de estudo, os ninhos foram amostrados em intervalos inferiores a 60 dias. Ninhos fundados foram coletados e trazidos para o laboratório. Foram amostrados 306 ninhos, contendo 894 células (523 em SC e 371 em LA).

No laboratório, casulos viáves de cada ninho foram transferidos para tubos de vidro transparente e mantidos em local escuro e à temperatura ambiente até a emergência dos adultos. Cada adulto emergido foi sexado, pesado e medido no comprimento de sua asa anterior, como descrito abaixo.

Mensurações. Foram medidos o diâmetro de cada ninho e o comprimento de cada célula de cria. $\mathrm{O}$ volume das células foi calculado usando-se a fórmula do volume do cilindro. Esta medida foi escolhida como índice de investimento maternal porque é possível obtê-la de maneira não-destrutiva, principalmente após a larva ter completado seu desenvolvimento. Além disso, o volume da célula de $T$. rogenhoferi correlaciona-se com a massa de aranhas nela aprovisionada (GARCIA \& Adis 1995; CAMILlO \& BRESCOVIT 1999).

Como índice de tamanho de corpo usou-se o comprimento da asa anterior (CAA), tomada ao longo da margem da asa, da base da tégula até sua extremidade. Em Trypoxylon Latreille, 1796, esta medida é boa indicadora do tamanho de machos e fêmeas, sendo indicativa da quantidade de alimento recebido pelo imaturo (Coville \& GRISwOLd 1983). 
Razão sexual. A razão sexual secundária foi determinada a partir dos indivíduos que emergiram no laboratório. Para verificar se o diâmetro dos ninhos-armadilha exerceu alguma influência sobre a razão sexual, foram tomados 34 ninhos em LA e 56 em SC nos quais todos os indivíduos completaram seu desenvolvimento. Os valores de razão sexual encontrados nestes ninhos, calculados como porcentagem de machos, foram transformados (arcoseno) e comparados com o diâmetro dos ninhos através de regressão linear.

Alocação sexual materna. De 273 células de cria foram determinados o volume, o número e a massa das aranhas estocadas. A relação entre o volume da célula de cria e a razão sexual foi investigada classificando-se os volumes em seis categorias contendo, aproximadamente, o mesmo número de observações (indivíduos produzidos). O volume médio das células de cria foi comparado com a proporção de machos produzidos utilizando-se regressão logística (TREXLER \& TRAVIS 1993; Molumby 1997).

Medidas do sucesso reprodutivo. Nas áreas de nidificação, a população de $T$. rogenhoferi pode ser dividida em indivíduos residentes (os estabelecidos em ninhos) e patrulheiros (os que estão à procura de locais para nidificação). Para verificar se o tamanho do corpo de machos e fêmeas influencia o grau de acesso a ninhos, no período de 14 a 19 de janeiro de 2001, em LA, indivíduos foram capturados, marcados, medidos e liberados. Neste período, a área de nidificação foi observada e anotados quais indivíduos (marcados ou não) estavam estabelecidos em ninhos. $\mathrm{O}$ teste $\mathrm{t}$ foi utilizado para verificar possíveis diferenças no tamanho de corpo entre as categorias 'residente' e 'patrulheira'. O teste de Levene foi empregado para verificar diferenças entre a variância do tamanho do corpo dessas duas categorias.

Taxa de aprovisionamento e fecundidade das fêmeas. Para verificar a relação entre o tamanho da fêmea e a taxa de aprovisionamento, ninhos ativos foram marcados e as fêmeas fundadoras coletadas e marcadas com tinta à base de nitrocelulose. Para isso, cada fêmea foi contida com auxílio de um pedaço de espuma porosa e lâmina de vidro. As fêmeas marcadas não tiveram seu comportamento alterado e, antes da liberação, foi anotado o comprimento de sua asa anterior. Com uma sonda, verificou-se até onde o ninho tinha sido construído e uma marca correspondente foi feita em sua parede externa. A retirada do ninho do campo obedeceu um intervalo de dois dias após sua localização. No laboratório, o ninho era aberto, o número de células construídas após a marca da sondagem, contado e as aranhas contadas e pesadas.

A taxa de aprovisionamento foi representada pelo número médio de aranhas coletadas por fêmea por dia, massa média de aranhas coletadas por dia, a massa média das aranhas estocadas nas células de cria e o número médio de células completadas por dia. Esta última medida servindo também como indicador de fecundidade. Estes valores foram comparados com o comprimento da asa da fêmea nidificante através de regressão linear.

No período de 23 a 29 de janeiro de 2001 foram realizadas observações do comportamento de nidificação de 23 fêmeas de $T$. rogenhoferi na área de SC e foi adotado como índice de fecundidade o número de ninhos fundados por cada fêmea.

\section{RESULTADOS}

Volume da célula de cria e aranhas estocadas. Os caracteres de tamanho de corpo, peso das aranhas estocadas e volume das células de cria seguiram distribuição normal para ambos os sexos de T. rogenhoferi (Komolgorov-Smirnov; $\mathrm{P}>0,20$ para todos os testes).

O volume da célula de cria foi significativamente correlacionado com o peso úmido $(\mathrm{R}=0,37 ; \mathrm{P}<0,05 ; \mathrm{GL}=44)$ e número $(\mathrm{R}=0,45 ; \mathrm{P}<0,01 ; \mathrm{GL}=44)$ das aranhas aprovisionadas. Não houve correlação entre a massa e o número de aranhas estocadas $(\mathrm{R}=0,25, \mathrm{P}>0,05 ; \mathrm{GL}=44)$.

Razão e investimento sexual. A razão sexual secundária em SC foi de 261 fêmeas para 183 machos, ou 1,43:1 ( $\pm 0,02 E P)$, o que difere estatisticamente de $1: 1\left(\chi_{(1)}^{2}=13,7 ; \mathrm{P}<0,01\right)$. Considerando-se o peso ao emergir, tem-se em SC, 61,3\% do investimento em fêmeas (ou 1,59:1; o que difere de 1:1; P < 0,001). Em LA, a razão sexual foi de 124 fêmeas para147 machos, ou 0,84:1 ( $\pm 0,03 E P)$, não diferindo de $1: 1\left(\chi_{(1)}^{2}=1,95 ; \mathrm{P}=0,16\right)$. Considerando-se o peso ao emergir, tem-se $55,9 \%$ do investimento em machos (ou 1,27:1; o que difere de 1:1; P < $0,001)$. Não há evidências de que a razão sexual tenha variado entre os ninhos amostrados $\left(\chi_{(13)}^{2}=19,37 ; \mathrm{P}=0,11\right.$ para os ninhos de SC e $\chi_{(14)}^{2}=9,86 ; \mathrm{P}=0,77$ para os ninhos de LA).

Há correlação entre o diâmetro do ninho-armadilha e o volume das células de cria presentes nele (Correlação de Spearman; $R=0,91 ; N=717 ; P<0,001)$. Nas duas populações verificou-se uma tendência de que em ninhos-armadilha de menor diâmetro foram produzidos maior número de machos. Entretanto, a razão sexual foi influenciada pelo diâmetro dos

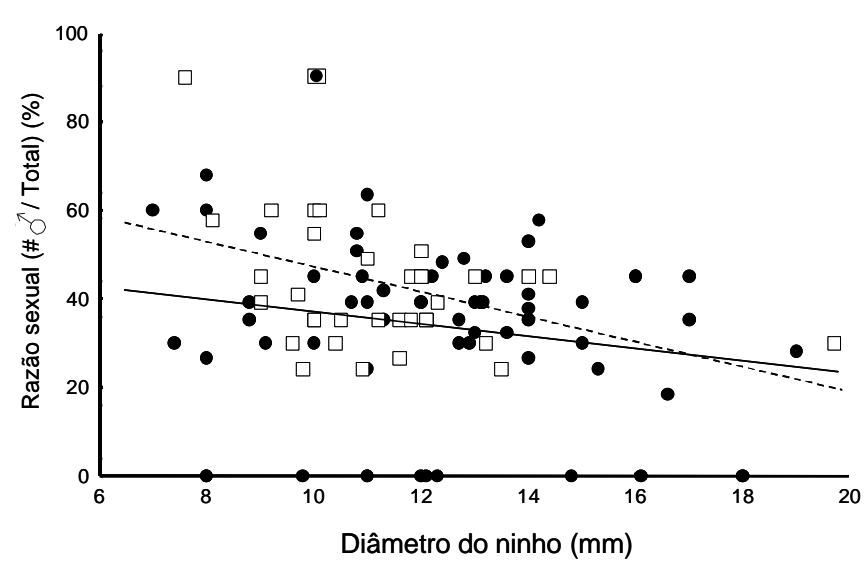

Fig. 1. Influência do diâmetro dos ninhos-armadilha utilizados em São Carlos (círculos; linha contínua) e em Luís Antônio (quadrados; linha tracejada) sobre a razão sexual de Trypoxylon rogenhoferi. 


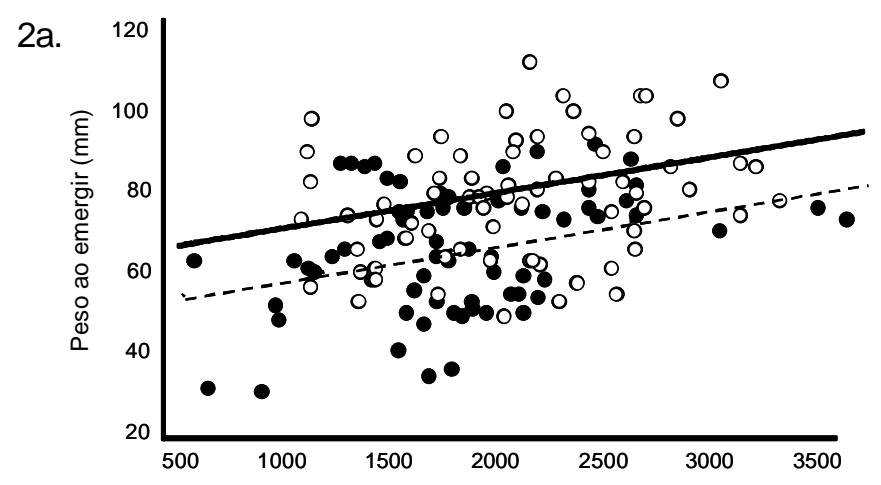

$2 b$.

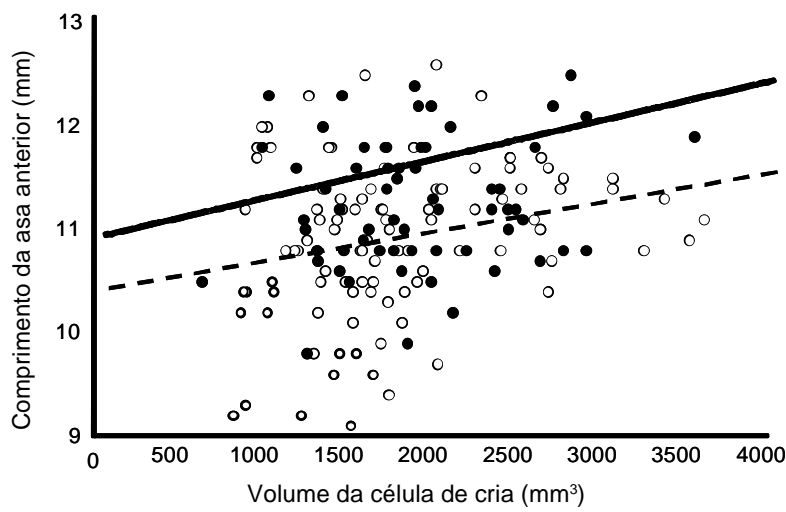

Fig. 2. Relação entre (2a) o volume da célula de cria e o peso ao emergir e (2b) o volume da célula de cria e o comprimento da asa anterior em Trypoxylon rogenhoferi. Círculos pretos indicam fêmeas; círculos brancos, machos. Regressões lineares significativas $(P<0,05)$ são indicadas pelas linhas contínuas (fêmeas) e tracejadas (machos).

ninhos-armadilha apenas em $\mathrm{LA}\left(\mathrm{F}_{1,35}=5,89 ; \mathrm{P}<0,05\right)$ (Fig. 1), onde também o diâmetro médio dos ninhos utilizados foi menor (teste de Mann-Whitney, $\mathrm{Z}=-3,39 ; \mathrm{P}<0,01)$. Porém, os ninhosarmadilha de SC apresentaram maior coeficiente de variação $(\mathrm{CV}=24,0 \%)$ do que os de LA $(7,8 \%)$ (teste $\mathrm{Z} ; \mathrm{P}<0,0001)$.

Volume da célula de cria e tamanho do corpo. As duas populações estudadas apresentaram valores semelhantes para os dados de tamanho de corpo e volume de células de cria; assim, os resultados dessas variáveis são apresentados conjuntamente.

Em T. rogenhoferi, o CAA apresentou correlação com o peso do adulto de ambos os sexos ao emergir (machos: $\mathrm{R}=$ 0,76; $\mathrm{P}<0,001 ; \mathrm{N}=121$; fêmeas: $\mathrm{R}=0,77 ; \mathrm{P}<0,05 ; \mathrm{N}=118$ ). Tanto o CAA como o peso do adulto, de ambos os sexos, foram função do volume da célula de cria em que ele foi produzido (Fig. 2a e 2b). Os machos foram menores do que as fêmeas $\left(\mathrm{t}_{(2), 579}=11,3 ; \mathrm{P}<0,001\right)$ e foram produzidos preferencialmente em células de menor volume (regressão logística; $\mathrm{y}=\exp (-0,40 \mathrm{x}+0,72) /\left[(1+\exp (-0,40 \mathrm{x}+0,72)] ; \chi_{(1)}^{2}=\right.$ 9,70; P<0,01) (Fig. 3).

Investimento materno. As fêmeas de ambas as localidades apresentaram padrões variáveis de aprovisionamento para a prole feminina e masculina, o que pode ter resultado em variações intrafamiliares (nidais) no tamanho do corpo. Para a progênie feminina e masculina das fêmeas de LA houve variação intrafamiliar significativa para CAA e volume da célula de cria (ANOVA; fêmeas: $\mathrm{F}_{25 ; 44}=2,1 ; \mathrm{P}<0,05$ para CAA; $\mathrm{F}_{20 ; 41}=67,12$; $\mathrm{P}<0,001$ para volume da célula de cria; machos: $\mathrm{F}_{31 ; 50}=1,83 ; \mathrm{P}$ $<0,05$ para o $\mathrm{CAA} ; \mathrm{F}_{18 ; 29}=8,6 ; \mathrm{P}<0,001$ para volume da célula de cria) e ainda para a progênie feminina houve variação intrafamiliar para o peso do adulto ao emergir $\left(\mathrm{F}_{16 ; 27}=2,35 ; \mathrm{P}<\right.$ $0,05)$ o que não aconteceu para a prole masculina $\left(\mathrm{F}_{37 ; 46}=0,92\right.$; $\mathrm{P}>0,05)$. Em SC, para a progênie feminina e masculina, houve variação intrafamiliar significativa para CAA e volume da célula de cria (ANOVA; fêmeas: $\mathrm{F}_{53 ; 138}=2,6 ; \mathrm{P}<0,001$ para CAA; $\mathrm{F}_{29}$; ${ }_{77}=38,14 ; \mathrm{P}<0,001$ para volume da célula de cria; machos: $\mathrm{F}_{43}$; ${ }_{77}=2,28 ; \mathrm{P}<0,01$ para $\mathrm{CAA} ; \mathrm{F}_{30 ; 36}=28,3 ; \mathrm{P}<0,001$ para volume da célula de cria), mas não para o peso do adulto ao emergir (ANOVA; fêmeas: $\mathrm{F}_{15 ; 30}=1,61 ; \mathrm{P}>0,05 ;$ machos: $\mathrm{F}_{3 ; 10}=0,94 ; \mathrm{P}$ $>0,05)$.

O tamanho da fêmea influenciou o tamanho da progênie feminina. Houve relação entre o CAA médio da prole feminina e o CAA materno. Entretanto, não houve influência do tamanho da mãe sobre o tamanho da progênie masculina. Por fim, não houve relação entre os tamanhos das progênies feminina e masculina (Fig. 4).

Taxas de aprovisionamento das fềmeas. $\mathrm{O}$ tamanho da fêmea influenciou seu sucesso no aprovisionamento do ninho. Fêmeas maiores capturaram maior massa de aranhas por dia do que fêmeas menores (Fig. 5). As fêmeas maiores também capturaram aranhas mais pesadas $\left(\mathrm{R}^{2}=0,46 ; \mathrm{y}=0,017 \mathrm{x}-0,126\right.$; $\mathrm{F}=13,4 ; \mathrm{GL}=17 ; \mathrm{P}<0,01)$ e aprovisionaram um número maior de células $\left(\mathrm{R}^{2}=0,36 ; \mathrm{y}=0,042 \mathrm{x}-2,89 ; 8,3 ; \mathrm{GL}=16 ; \mathrm{P}<0,05\right)$. Não houve, porém, relação significativa entre o tamanho da fêmea e o número de aranhas capturadas por dia $(\mathrm{P}=0,40)$.

Fecundidade. Nas populações de T. rogenhoferi, a fecundidade das fêmeas é bastante variável. Em SC, de um

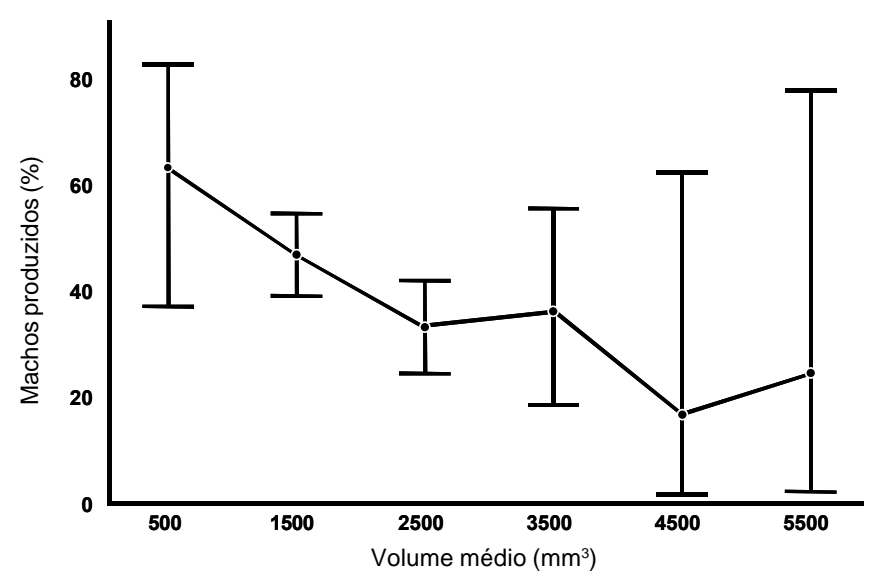

Fig. 3. Proporção de machos de Trypoxylon rogenhoferi produzidos em seis categorias de volume $\left(\mathrm{mm}^{3}\right)$ de células de cria. Nas linhas, o ponto representa a proporção média de machos produzidos em cada volume e as barras, o intervalo de confiança binomial de $95 \%$. 


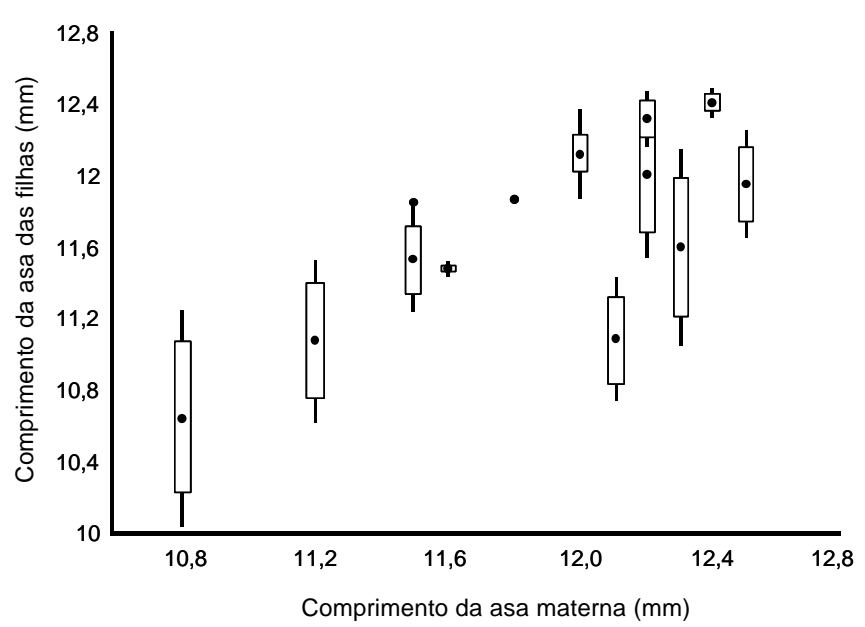

Fig. 4. Comprimento da asa anterior materna versus o comprimento da asa da progênie feminina. Os círculos representam médias; retângulos o erro padrão e as barras, o desvio padrão (famílias com uma única filha são representadas apenas pelo círculo).

conjunto com 10 ninhos-armadilha, uma única fêmea fundou quatro deles e outra, dois. Posteriormente, a primeira fêmea fundou outro ninho em outro conjunto de ninhos-armadilha, enquanto a segunda não foi mais observada na área.

Possivelmente, poucas fêmeas são responsáveis pela produção da maior parte da prole de uma área (Fig. 6). A maior fecundidade (número de ninhos fundados) estaria relacionada ao maior tamanho de corpo (veja o número de células construídas por fêmeas maiores no item anterior) e as fêmeas forrageariam até morrerem, não diminuindo sua intensidade de forrageamento com a idade.

Residentes e patrulheiros. Aparentemente, em LA, o tamanho do corpo não é fator determinante no acesso a ninhos $\left(\mathrm{t}_{(2), 36}=0,62 ; \mathrm{P}=0,53\right.$ para fêmeas; $\mathrm{t}_{(2), 86}=0,21 ; \mathrm{P}=0,83$ para machos). Também não há evidências de que seleção

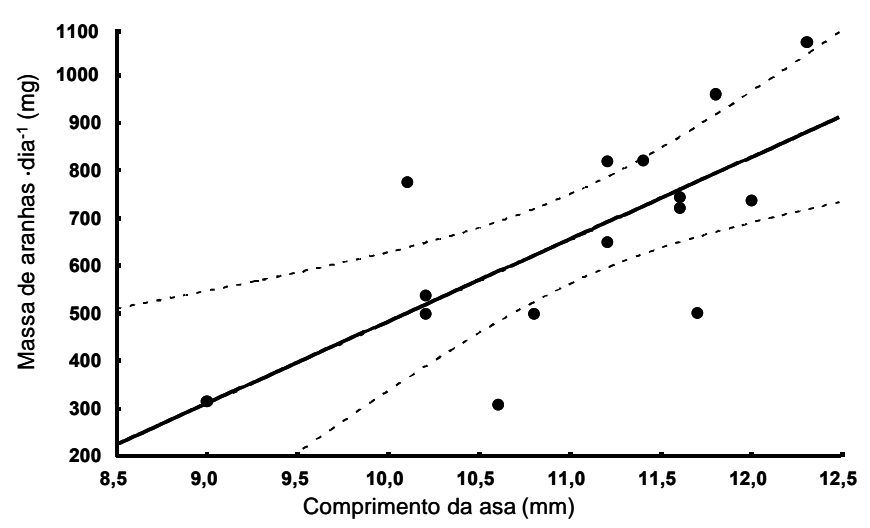

Fig. 5. Relação entre a massa de aranhas capturadas por dia e o tamanho da fêmea (CAA) de Trypoxylon rogenhoferi. A linha tracejada representa o intervalo de confiança de $95 \%$.

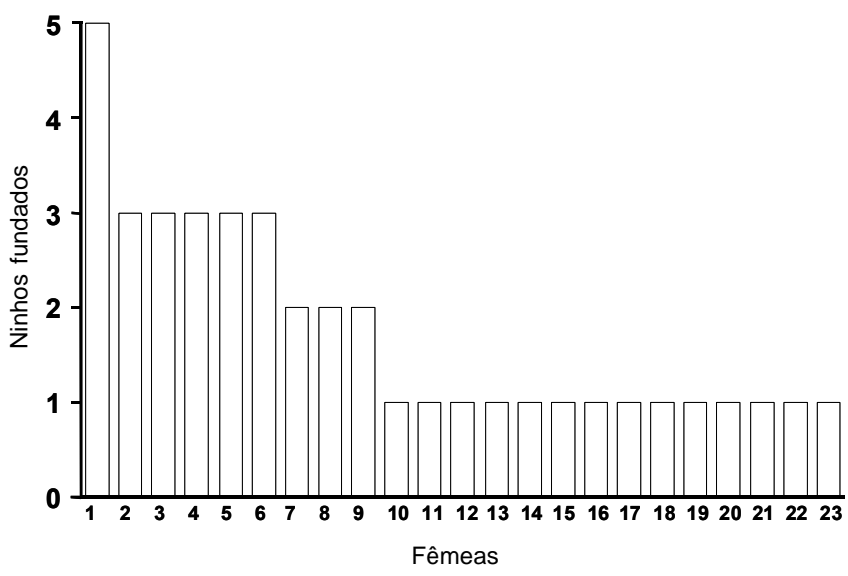

Fig. 6. Número de ninhos fundados por 23 fêmeas (1 a 23) de Trypoxylon rogenhoferi em São Carlos. A fecundidade observada (considerada como ninhos fundados) está ordenada de forma decrescente.

estabilizadora esteja agindo sobre os residentes ou patrulheiros (machos ou fêmeas) durante o período de estudo (teste de Levene; $\mathrm{F}=0,41$ para machos; $\mathrm{F}=0,42$ para fêmeas; $\mathrm{P}>0,05$ para ambos).

\section{DISCUSSÃO}

Investimento igual ou desigual? Os trabalhos realizados por Coville \& Coville (1980), CAmillo et al. (1993, 1994) e GARCIA \& ADIS (1995) mostram que a razão sexual em espécies de Trypoxylon é variável espacial e temporalmente, o que também foi observado neste estudo. Esta variação pode ser conseqüência de flutuações na abundância das presas disponíveis para as fêmeas nidificantes, as quais adotariam estratégias de alocação sexual condicional (em condições de recursos escassos o investimento seria dirigido ao sexo menos dispendioso; veja Strohm \& Linsenmair 1997a; West \& SHELDON 2002). Vale ressaltar que, em amostragens com ninhosarmadilha, havendo predomínio ou exclusividade de diâmetros reduzidos, são produzidos mais machos (KROMBEIN 1967; Coville \& Coville 1980; Camillo et al. 1993, 1994). O mesmo deve ocorrer em condições naturais, já que diâmetro da cavidade e volume da célula de cria estão relacionados. Por outro lado, os dados de SC indicam que, havendo diversidade de diâmetros, os ninhos com maior diâmetro são preferencialmente utilizados, possibilitando a produção de prole de ambos os sexos.

Em SC, a produção de fêmeas é quase $50 \%$ maior que a de machos. Desvios deste tipo podem ser atribuídos a (i) competição local por acasalamento e/ou endocruzamentos (HAMILTON 1967; CowAN 1991) ou (ii) aumento local de recuros (Schwarz 1988). Aparentemente, (i) não se aplica a esta população, já que não há indícios de endogamia acentuada e, em T. rogenhoferi, os machos deixam o ninho depois das fêmeas (R. C. Peruquetti observação pessoal), o que de certa maneira dificulta o acasalamento entre irmãos. Ninhos de maior diâmetro, implicando em volumes maiores das células de cria, poderiam 
desempenhar algum papel na maior produção de fêmeas. Entretanto, a despeito dos ninhos instalados em SC terem maior diâmetro médio do que os instalados em LA, isso não acontece. $\mathrm{O}$ volume médio das células que produziram machos ou fêmeas na população de SC não difere estatisticamente daqueles da população de LA (teste $\mathrm{t} ; \mathrm{P}>0,20$ para ambos os sexos; fêmeas $\mathrm{GL}=184$; machos: $\mathrm{GL}=134$ ), onde o diâmetro do ninho influênciou a maior produção de machos. O mesmo acontece quando consideramos o volume médio de todas as células amostradas em cada local (teste t; P > 0,50; GL = 702).

Desta forma, a hipótese sobre o aumento local de recursos (Schwarz 1988) pode ser uma explicação possível. A despeito da igualdade dos volumes das células de cria (índice que influencia o tamanho do adulto, veja abaixo), a população de SC apresenta indivíduos dos dois sexos maiores dos que os da população de LA (teste $\mathrm{t}$; $\mathrm{P}<0,0001$ para ambos os sexos; fêmeas, $\mathrm{GL}=310$; machos, $\mathrm{GL}=259$ ). Já que em Trypoxylon o tamanho do adulto é função da quantidade de alimento ingerido pela larva e este é bom estimador do investimento materno (MolumBy 1997), o maior tamanho dos indivíduos da população de SC poderia estar relacionado ao relaxamento de fatores que limitariam a produção de prole de maior tamanho corporal. Nesse caso, haveria farta disponibilidade de presas [em SC, a diversidade (Shannon-Weaver) de aranhas capturadas por $T$. rogenhoferi foi 2,34 vezes maior que aquela de $\mathrm{LA}(\mathrm{P}<0,0001)$; R.C. Peruquetti observação pessoal] e a pressão de parasitismo seria baixa (em LA a taxa de parasitismo é 10 vezes maior que a de SC, R.C. Peruquetti observação pessoal). Baixa pressão de parasitismo permitiria que as células de cria permanecessem mais tempo abertas e pudessem ser melhor aprovisionadas pelas fêmeas como foi observado em T. politum Say, 1837 (BROCKMANN \& GRAFEN 1989).

Os dados de investimento sexual reforçam os de razão sexual. Entretanto, de maneira geral, machos e fêmeas de Sphecidae são dimórficos em relação ao tamanho do corpo, sendo machos menores do que fêmeas (Evans \& WestEBERHARD 1970), o que pode gerar erros ao considerar-se o peso dos indivíduos na determinação de investimento sexual (Helms 1994).

Considerando-se o volume das células de cria como índice de investimento maternal, em SC a produção de uma fêmea custou 1,13 vezes a produção de um macho. Com base nesta medida, o princípio de FISHER (1930) prediz que, nesta população, a razão sexual seria de 1,13 (ou 56,5\%) machos para cada fêmea. A população estudada de SC produziu $41,2 \%$ de machos, o que difere estatisticamente do esperado pelo princípio de Fisher $\left(\chi_{1}^{2}=9,18 ; \mathrm{P}<0,01\right)$. Em LA, o custo de uma fêmea foi 1,13 vezes o de um macho; neste caso, porém, dentro do esperado pelo princípio de Fisher $\left(\chi_{1}^{2}=0,38 ; \mathrm{P}=\right.$ $0,56)$.

Infelizmente, não há dados de outros trabalhos com $T$. rogenhoferi para comparações. Nem é possível determinar a razão das diferenças observadas; talvez o que foi dito anteriormente sobre maior abundância de recursos e baixas taxas de parasitismo em SC possa explicar algo do observado, mas com base apenas neste estudo é difícil qualquer conclusão.
Em um estudo de sete anos com T. politum, Brockmann \& GRAFEN (1992) concluíram que, nesta espécie, o investimento materno é maior em machos, diferentemente do predito pelo modelo de Fisher.

De qualquer modo, ponderar investimento materno com apenas uma variável é, no mínimo, subestimá-lo. Vários aspectos da existência da fêmea, como risco de predação, dificuldade em localizar locais para nidificação e presas e risco de acasalamento, estão em jogo no momento da produção de uma progênie (Molumby 1997). Certamente, estudos futuros em Trypoxylon poderão permitir testar hipóteses ou modelos sobre investimento sexual em Hymenoptera.

Tamanho do corpo e valor adaptativo. As fêmeas de Trypoxylon são maiores do que os machos (SAKAGAMI et al. 1990; Brockmann 1992; Garcia \& Adis 1995; Molumby 1997; Camillo 1999; Camillo \& Brescovit 1999), o que pode ser resultado do investimento da fêmea fundadora (Molumby 1997). As populações estudadas de T. rogenhoferi adequaram-se a todos os pressupostos dos modelos de GreEn (1982) e BROCKMANN \& GRAFEN (1992). O peso da aranhas estocadas segue distribuição normal. Assim, a quantidade de provisão disponível para um indivíduo qualquer pode ser vista como variável contínua aleatória. A fêmea de T. rogenhoferi oviposita na última aranha depositada em cada célula de cria e, deste modo, ela pode, teoricamente, escolher o sexo de sua prole (fertilizando ou não o ovo) de acordo com a disponibilidade de provisão. Para machos e fêmeas o tamanho do corpo foi função da quantidade de alimento recebido pela larva. Todavia, a progênie feminina se beneficia mais da maior quantidade de provisão recebida do que a progênie masculina.

Estas evidências sugerem que as fêmeas com maior tamanho de corpo teriam grande vantagem adaptativa, pois coletaram maior massa de aranhas por dia, as aranhas coletadas foram maiores e elas completaram maior número de células de cria por dia do que fêmeas menores. Provavelmente, a fecundidade das fêmeas pode ser geometricamente distribuída, com poucas fêmeas produzindo a maior parte da prole viável de uma área. Neste caso, as vantagens aparentes podem ser conseqüência apenas do aumento da taxa de forrageamento. Fêmeas maiores seriam capazes de caçar mais rápido aranhas maiores e completar mais rapidamente suas células de cria, do que fêmeas menores. Do ponto de vista da seleção para tamanho do corpo, fêmeas que receberam maior provisão enquanto larvas seriam selecionadas favoravelmente em relação às que receberam menos provisão.

$\mathrm{O}$ aumento do valor adapativo das fêmeas associado ao aumento do tamanho do corpo já foi detectado em outras espécies de vespas e abelhas com aprovisionamento massal e, em todas, maior tamanho de corpo resulta em taxas diferenciadas de forrageamento, caça, aprovisionamento e construção de células de cria (AlCock 1979; Cowan 1991; Molumby 1997; Strohm \& Linsenmair 1997b, 2000).

Não há evidência de seleção para tamanho do corpo dos machos de T. rogenhoferi. Mas, como apenas o acesso aos ninhos foi adotado como indicativo de sucesso reprodutivo, 
esta evidência pode ser falha. Em espécies cujos machos lutam ou defendem territórios para ter acesso a companheiras, machos com tamanhos diferenciados podem ter maior vantagem adaptativa (Alcock 1991; CowAN 1991; CoElHo \& HollidAY 2001). Entretanto, não há evidências de que machos de Trypoxylon defendam territórios de acasalamento. Além disso, não foram observadas diferenças de tamanho de corpo entre machos residentes e patrulheiros de $T$. politum (BROCKMANN 1992; Molumby 1997) e Philanthus triangulus (Fabricius, 1775) (STROHM \& LeChNER 2000).

O comportamento de guarda de ninhos ativos por machos é restrito a alguns representantes de Cerceris Latreille, 1796, Dynatus Lepeletier, 1845, Tachytes Panzer, 1806, Oxybelus Latreille, 1796, Pison Jurine in Spinola, 1808 e Trypoxylon (BoHART \& MenKe 1976; K yMSEy 1978; HoOK \& MATTHEWs 1980; Matthews 1991; Banks 1995; Hanson \& Menke 1995; BROCKMANN 1996). Tal comportamento, provavelmente, surgiu independentemente (uma possível exceção está em Trypoxylini, envolvendo Trypoxylon e Pison; ANTROPOv 1990) nos diferentes grupos de Sphecidae, sendo derivado do hábito territorial do macho (Alcock et al.1978; BrockMANn \& GRAFEN 1989). É interessante notar que o macho que guarda um ninho se beneficia deste comportamento apenas se for pai da progênie feminina. Molumby (1997) sugere que dimorfismo sexual poderia facilitar a guarda do ninho pelo macho de Trypargilum já que, em muitas espécies desse subgênero, as fêmeas são maiores do que os machos (COVILLE \& CovILle 1980; BROCKMANN 1992; GARCIA \& AdIs 1995). Dessa forma, o macho 'ajudaria' sua parceira a aprovisionar melhor as células de cria (por exemplo, compactando as aranhas capturadas) para que prole feminina fosse produzida.

Volume da célula de cria e sexo da prole. Os resultados deste estudo estão de acordo com as observações feitas em outros himenópteros com aprovisionamento massal: a progênie feminina recebe maior quantidade de alimento (caracterizada pelo maior volume da célula de cria) do que a progênie masculina (Brockmann \& Grafen 1989; Cowan 1991; Garcia \& Adis 1995; Molumby 1997). Entretanto, como ocorre em T. politum (Molumby 1997), entre os ninhos a alocação de recursos para os dois sexos não é fixa (ao contrário do que acontece dentro de um mesmo ninho; teste $\mathrm{F}_{2 / 5 ; 88 / 91}$; $\mathrm{P}<0,05$ para ambos os sexos em todos os testes), o que poderia gerar variações no tamanho do corpo entre os adultos. Isto seria consequiência da adoção pelas fêmeas nidificantes de estratégias de aprovisionamento diferenciadas. Isto seria interessante em um contexto evolutivo, considerando-se que o comportamento de aprovisionamento da mãe pode ser, em algum grau, transmitido à filha (Molumby 1997).

Fêmeas maiores produzem filhas maiores, mas não necessariamente filhos maiores. Esta relação entre o tamanho da mãe e o da filha indica que fêmeas maiores têm realmente maior valor adaptativo. Elas não produzem simplesmente muitas fêmeas pequenas e de baixo valor adaptativo. A produção de fêmeas grandes garante o maior sucesso reprodutivo da fêmea, já que suas filhas têm potencial para garantir a representatividade de seus genes nas gerações futuras. Observações semelhantes foram feitas nas vespas Sceliphron assimile (Dahlbom, 1843) (FREEMAN 1981), T. politum (MOLUMBY 1997) e Philantus triangulum (STROHM \& LinSENMAIR 1997b) e na abelha Xylocopa sulcatipes Maa, 1970 (STARK 1992). Molumby (1997) sugere que, em T. politum, o tamanho do corpo seja, mesmo que parcialmente, maternalmente herdado. Larvas fêmeas que recebem muito alimento se desenvolvem em fêmeas maiores que fornecerão maior quantidade de alimento à sua progênie feminina. Este tipo de herança materna, em que apenas as fêmeas são beneficiadas, tem propriedades muito distintas da herança genética simples (KIRKPATRICK \& LANDE 1989) e pode ser responsável pela produção de variação sobre a qual a seleção natural age (MousseAu \& Fox 1998). O presente estudo indica que mecanismos semelhantes poderiam estar atuando nas populações de $T$. rogenhoferi.

Agradecimentos. A Sérvio T. P. Amarante (Museu de Zoologia, USP) pela identificação de Trypoxylon rogenhoferi. À EMBRAPA (Faz. Canchim - São Carlos) pela permissão de coleta do material na área de sua responsabilidade. À Secretaria do Meio Ambiente do Estado de São Paulo, pela permissão de coleta de material biológico nas áreas da Estação Ecológica Jataí (Luís Antônio, SP). A Alan Molumby (Universidade de Chicago / USA) pelos esclarecimentos sobre a biologia de Trypoxylon politum e uso de alguns procedimentos estatísticos, leitura e correção do abstract. À FAPESP (processo no. 98/16930-0) pelo auxílio financeiro.

\section{REFERÊNCIAS}

ALCOCK, J. 1979. The relation between female body size and provisioning behavior in the bee Centris pallida Fox (Hymenoptera: Anthophoridae). Journal of the Kansas Entomological Society 52: 623-632.

Alcock, J. 1991. Adaptive mate guarding by males of Ontholestes cingulatus (Coleoptera: Staphylinidae). Journal of Insect Behavior 4: 763-771.

Alcock, J.; E. M. Barrows; G. Gordh; L. J. Hubbard; L. Kirkendall, D. W. Pyle; T. L. Ponder \& F. G. Zalom. 1978. The ecology and evolution of male reproductive behaviour in the bees and wasps. Zoological Journal of the Linnaean Society 64: 293-326.

Alexander, R. D. \& P. W. Sherman. 1977. Local mate competition and parental investment in social insects. Science 196: 494-500.

Antropov, A. V. 1990. Another nest-guarding male of Pison. Sphecos 20: 20 .

Banks, D. 1995. Male defense in the digger wasp Cerceris binodis (Hymenoptera: Sphecidae). Journal of Hymenoptera Research 4: 77-79.

Bohart, R. M. \& A. S. Menke. 1976. Sphecidae wasps of the world. A generic revision. Berkeley, University of California Press, 695 p.

Bourke, A. F. G. 1997. Hymenopteran sex allocation. Trends in Ecology and Evolution 12: 488.

Brockmann, H. J. 1992. Male behavior, courtship and nesting in Trypoxylon (Trypargilum) monteverdeae (Hymenoptera: Sphecidae). Journal of the Kansas Entomological Society 65: 66-84.

BrockmanN, H. J. 1996. Cooperative breeding in wasps and vertebrates: the role of ecological constraints, p. 347-371. In: J. C. Снов \& B. J. CRESPI (eds.). The evolution of social behavior in insects and arachnids. Cambridge, Cambridge University Press, $541 \mathrm{p}$.

Brockmann, H. J. \& A. GRAFEN. 1989. Mate conflict and male behaviour in a solitary wasp, Trypoxylon (Tripargilum) politum (Hymenoptera: Sphecidae). Animal Behaviour 37: 232-255.

Brockmann, H. J. \& A. GRAFEN. 1992. Sex ratios and life-history patterns of a solitary wasp, Trypoxylon (Trypargilum) politum (Hymenoptera: Sphecidae). Behavioral Ecology and Sociobiology 30: 7-27. 
Camillo, E. 1999. Bionomics of Trypoxylon (Trypagilum) antropovi and Trypoxylon (Trypargilum) aestivale (Hymenoptera, Sphecidae). Inheringia 87: 29-36.

CAmillo, E. \& A. D. Brescovit. 1999. Aspectos biológicos de Trypoxylon (Trypargilum) lactitarse Saussure e Trypoxylon (Trypargilum) rogenhoferi Kohl (Hymenoptera: Sphecidae) em ninhos-armadilhas, com especial referência a suas presas. Anais da Sociedade Entomológica do Brasil 28: 251-262.

Camillo, E.; C. A. Garófalo \& J. C. Serrano. 1994. Observações sobre biologia de Trypoxylon (Trypargilum) rogenhoferi Koh (Hymenoptera: Sphecidae). Anais da Sociedade Entomológica do Brasil 23: 299-310.

Camillo, E.; C. A. Garófalo; G. Muccillo \& J. C. Serrano. 1993. Biological observation on Trypoxylon (Trypargilum) lactitarse Saussure in Southeastern Brazil (Hymenoptera, Sphecidae). Revista Brasileira de Entomologia 37: 769-778.

Coelho, J. R. \& C. W. Holliday. 2001. Effects of size and flight performance on intermale mate competition in the cicada killer, Sphecius speciosus Druty (Hymenoptera: Sphecidae). Journal of Insect Behavior 14(3): 345-351.

Coville, R. E. \& C. GRIswold. 1983. Nesting biology of Trypoxylon xanthandrum in Costa Rica with observation on its spider prey (Hymenoptera: Sphecidae; Araneae: Senoculidae). Journal of the Kansas Entomological Society 56(2): 205-216.

Coville, R. E. \& P. L. Coville. 1980. Nesting biology and male behavior of Trypargilum tecnoctitlan in Costa Rica (Hymenoptera: Sphecidae). Annals of the Entomological Society of America 73: 110-119.

Cowan, D. P. 1991. The solitary and presocial Vespidae, p. 33-73. In: K. G. Ross \& R. W. Matthews (eds.). The social biology of wasps. Ithaca, Cornell University Press, $678 \mathrm{p}$.

Chapuisat, M. \& L. Keller. 1999. Testing kin selection with sex allocation data in eusocial Hymenoptera. Heredity 82: 473-478.

Crozier R. H. \& P. Pamilo. 1996. Evolution of social insect colonies. Sex allocation and kin selection. In: R. M. MAY \& P. H. HARVEY (eds.). Oxford series in ecology and evolution. New York, Oxford University Press, $306 \mathrm{p}$.

DeslipPe, R. J. \& R. SAVolainen. 1995. Sex investment in a social insect: the proximate role of food. Ecology 76: 375-382.

Evans, H. E. \& M. J. West-eberhaRd. 1970. The wasps. Devon, David \& Charles Newton Abbot, $265 \mathrm{p}$.

FISHER, R. A. 1930. The genetical theory of natural selection. Oxford, Clarendon Press, $230 \mathrm{p}$

Flanders, S. E. 1965. On the sexuality and sex ratios of hymenopterous populations. American Naturalist 93: 489-494.

Freeman, B. 1981. Parental investment, maternal size, and population dynamics in a solitary wasp. American Naturalist 117: 357-362.

Frohlich, D. R. \& V. J. Tepedino. 1986. Sex ratio, parental investment, and interparent variability in nesting success in a solitary bee. Evolution 40: 142-151.

Garcia, M. V. B. \& J. Adis. 1995. Comportamento de nidificação de Trypoxylon (Trypargilum) rogenhoferi Kohl (Hymenoptera, Sphecidae) em uma floresta inundável de várzea na Amazônia Central. Amazoniana 13: 259-282.

Gauld, I. D. \& P. E. Hanson. 1995. The biology of Hymenoptera, p. 2088. In: P. E. Hanson \& I. A. GAuld (eds.). The Hymenoptera of Costa Rica. New York, Oxford University Press, 893 p.

GreEN, R. F. 1982. Optimal foraging and sex ratio in parasitic wasps. Journal of Theoretical Biology 95: 43-48.

Hamilton, W. D. 1967. Extraordinary sex ratios. Science 156: 477-488.

Hanson, P. E. \& A. S. Menke. 1995. The sphecid wasps (Sphecidae), p 621-649. In: P. E. Hanson \& I. A. Gauld (eds.). The Hymenoptera of Costa Rica. New York, Oxford University Press, 893 p.

Helms, K. R. 1994. Sexual size dimorphism and sex ratios in bees and wasps. American Naturalist 143: 418-434.

Ноок, A. W. \& R. W. Matтhews. 1980. Nesting biology of Oxybelus sericeus with a discussion of nest guarding by males sphecid wasps (Hymenoptera). Psyche 87: 21-37.

Kimsey, L. S. 1978. Nesting and male behavior in Dynatus nigripes spinole (Lepeletier). Pan-Pacific Entomologist 54: 64-68.

KirKPatRICK, M. \& R. LANDE. 1989. The evolution of maternal characters. Evolution 43: 485-503.

Krombein, K. V. 1967. Trap-nesting wasps and bees: life histories, nests and associates. Washington, Smithsonian Press, $570 \mathrm{p}$.

Matthews, R. W. 1991. Evolution of social behavior in sphecid wasps, p. 570-602. In: K. G. Ross \& R. W. MatThews (eds.). The social biology of wasps. Ithaca, Cornell University Press, 678 p.

Molumby, A. 1997. Why make daughter larger? Maternal sex-allocation and sex-dependent selection for body size in a mass-provisioning wasp, Trypoxylon politum. Behavioral Ecology 8: 279-287.

Mousseau, T. A. \& C. W. Fox. 1998. The adaptive significance of maternal effects. Trends in Ecology and Evolution 13: 403-407.

Оки, S. \& T. Nishida. 1999. Factors affecting female-biased sex ratio in trap-nesting wasp, Trypoxylon malaisei. Researches on Population Ecology 41: 169-175

Оке, S. \& T. Nishida. 2001. Presence of single-sex broods under local mate competition in Trypoxylon malaisei (Hymenoptera: Sphecidae): Adaptation or maladaptation? Annals of the Entomological Society of America 94: 550-554.

SAKAGAMI, S. F.; N. GobBI \& R. ZuCCHI. 1990. Nesting biology of a quasisocial sphecid wasp Trypoxylon fabricator I. Nests and Inhabitants. Japanese Journal of Entomology 58: 846-862.

Schwarz, M. P. 1988. Local resource enhancement and sex ratios in a primitively social bee. Nature 331: 346-348.

Stark, A. E. 1992. Sex ratio and maternal investment in the multivoltine large carpenter bee, Xylocopa sulcatipes (Apoidea: Anthophoridae). Ecological Entomology 17: 160-166.

Strohm, E. \& K. Lechner. 2000. Male size does not affect territorial behaviour and life history traits in a sphecid wasp. Animal Behaviour, 59 183-191.

Strohm, E. \& K. E. Linsenmair. 1997a. Low resource availability causes extremely male-biased investiment ratios in the European beewolf, Philanthus triangulus F. (Hymenoptera, Sphecidae). Proceedings of the Royal Society of London B, Biological Sciences 264: 423-429.

Strohm, E. \& K. E. Linsenmair. 1997b. Female size affects provisioning and sex allocation in a digger wasp. Animal Behaviour 54: 23-34.

Strohm, E. \& K. E. LinsEnMAir. 1999. Measurement of parental investment and sex allocation in the European beewolf Philanthus triangulus $\mathrm{F}$. (Hymenoptera: Sphecidae). Behavioral Ecology and Sociobiology 47: 76-88.

Strohm, E. \& K. E. Linsenmair. 2000. Allocation of parental investment among individual offspring in the European beewolf Philanthus triangulum F. (Hymenoptera: Sphecidae). Biological Journal of the Linnean Society 69: 173-192.

Trexler, J. C. \& J. Travis. 1993. Nontradicional regression analyses. Ecology 74: 1629-1637.

Trivers, R. L. \& H. Hare. 1976. Haplodiploidy and the evolution of the social insects. Science 191: 249-263.

YANEGA, D. 1996. Sex ratio and sex allocation in sweat bees (Hymenoptera: Halictidae). Journal of the Kansas Entomological Society 69 : 98-115.

WCisLo, W. T. 1996. Parasitism rates in relation to nest site in bees and wasps (Hymenoptera: Apoidea). Journal of Insect Behavior 9(4): 643-656.

West, S. A. \& B. C. Sheldon. 2002. Constraints in the evolution of sex ratio adjustment. Science 295: 1685-1688. 